Original Research Paper

\title{
The Moderating Effect of Sibling Delinquency on Risky Behavior during Emerging Adulthood
}

\author{
${ }^{1}$ F. Ryan Peterson, ${ }^{2}$ Leslie Gordon Simons, ${ }^{3}$ Adriatik Likcani and ${ }^{4}$ Katherine Hickey \\ ${ }^{I}$ Educational Leadership and Human Development, University of Central Missouri, United States \\ ${ }^{2}$ Department of Sociology, University of Georgia, United States \\ ${ }^{3}$ Educational Leadership and Human Development, University of Central Missouri, United States \\ ${ }^{4}$ Center for Social Justice, University of Oklahoma, United States
}

\author{
Article history \\ Received: 14-12-2016 \\ Revised: 02-03-2017 \\ Accepted: 12-08-2017 \\ Corresponding author: \\ F. Ryan Peterson \\ Educational Leadership and \\ Human Development, \\ University of Central \\ Missouri, United States \\ Email: rpeterson@ucmo.edu
}

\begin{abstract}
This study examines the relationship between sibling delinquency and respondent risky behavior of emerging adults. This study attempts to understand the influence a sibling has on deviant behavior, sexual behavior and substance use during emerging adulthood. Sibling support and sibling contact were the two components of sibling relationships that were examined. A social learning theory framework was used. It was hypothesized that an individual who has high contact and support from a deviant sibling would be more likely to engage in risky behavior, be more sexually active and have increased alcohol use. The sample was comprised of 690 undergraduates enrolled in a large state university. A test of the moderating effects of sibling support and contact was conducted. Results indicate that there is a moderating relationship between the influence of sibling delinquency on respondent deviance, sexual permissiveness and alcohol use for females. As contact and support with a delinquent sibling increases, the level of respondent deviance, sexual permissiveness and alcohol use also increases.
\end{abstract}

Keywords: Sibling, Delinquency, Emerging Adulthood, Sexuality, Alcohol

\section{Introduction}

Sibling relationships are an essential and unique component of individual and family relationships, due in part to the longevity of the relationships and the level of shared intimacy (Brody, 1998; Dunn, 2005; Kramer and Bank, 2005; McHale et al., 2012; 2001). While existing literature tends to focus on sibling relationships in childhood and adolescence, there is a dearth of knowledge on sibling relationships in emerging adulthood, which includes individuals between the ages of 18 and 25 years old. The research that has been conducted regarding this population has largely been limited to the developmental transition to adulthood (Arnett, 2014; Arnett and Tanner, 2005) and psychosocial outcomes (Arnett, 2000). The specific characteristics of emerging adulthood, particularly identity exploration, self-perception and an increased likelihood of sexual permissiveness, render it an interesting time in human development to consider sibling relationships. Indeed, individuals during emerging adulthood are negotiating their place in their families of origin and exploring their role in relationships. Furthermore, the involuntary nature of sibling relationships in childhood changes once individuals leave home: Interactions and communication occur because of choice and no longer because of forced proximity in the household.

Current research indicates a strong influence of the sibling relationship on externalizing behavior, whether positive or negative (Feinberg et al., 2013; Keeton et al., 2015; Rowan, 2016). Therefore, sibling relationships can be a source of resilience or contribute to risky behavior. Deviance and delinquency have traditionally been defined in social science literature as behaviors that compromise the well-being of others (Bennett and Robinson, 2000). The connection between sibling relationships and deviance may be due to several factors: The observation of deviant behavior in a sibling, exposure to behavior that promotes and encourages deviancy, such as positive attitudes and encouragement to participate in delinquent behavior (Snyder et al., 2005) and pre-existing conflict in the sibling relationship (Kramer and Bank, 2005; Pike et al., 2005). Genetic research has found that the influence of siblings on risky behavior is often outweighted by social factors instead of pre-determined genetic factors (McGue et al., 1996; Natsuaki et al., 
2009). This further highlights the importance of identifying and understanding the contextual factors surrounding behavior. By focusing exclusively on emerging adults, the current study addresses a gap in the literature which rarely frames sibling relationships within a developmental context beyond adolescence.

Illuminating the specific causes and effects of sibling relationships in emerging adulthood on risky behavior will provide strong implications for both practitioners and researchers. Bandura (1977) highlights the degree to which learning occurs in a social context in his social learning theory, which served as the theoretical framework of the study. Individuals cannot be divorced from the environments in which they position themselves or are immersed in at birth. By focusing on sibling relationships, this study provides a contextual understanding of risky behavior which can inspire clinical practices, program interventions, educational practices and family services. It was hypothesized that an individual who has high contact and support from a delinquent sibling would be more likely to engage in deviant behavior, be more sexually permissive and demonstrate increased alcohol use.

\section{Literature Review}

\section{Emerging Adulthood}

Arnett (2000) coined the term "emerging adulthood" to describe 18 to 25 year olds and identified several key principles affecting this demographic. First, the delay of marriage, child-rearing and the pursuit of higher education highly influence their transition from adolescence to adulthood. There is a certain "volition" (Arnett, 2000, p. 469) during the 18-to-25-year-old window that releases emerging adults from the marital, familial and professional expectations that were preponderant past the age of 30 . Second, they experience an ambivalent identity, struggling to negotiate characteristics that they perceive as belonging to both adolescence and adulthood. While they often conceptualize adulthood around social status and recognition, they are primarily concerned with character properties and qualities during emerging adulthood, in particular financial independence and "responsibility for one's self" (Arnett, 2000, p. 473). Third, it is a time of identity exploration. Professional settings provide the opportunity to consider life-goals, strengths and weaknesses and passions. Emerging adulthood is an ideal time to explore introspective questions such as "what kind of work am I good at?" and "what kind of work would I find satisfying for the long term?" Arnett (2000, p. 474). Finally, Arnett (2000) noted that unprotected sex, substance abuse and binge drinking are most common among emerging adults. Researchers hypothesize that the exploratory and curious nature of emerging adults translates into a desire to experience a wide variety of situations before committing to "adult roles."

The common denominator in Arnett's principles is decision-making: Exploring, tentatively or aggressively, new ways of social, professional and relational living.

\section{Sibling Relationships and Deviancy}

The influence siblings have on one another has been documented throughout the life course (Cicirelli, 1995), particularly throughout childhood (McHale et al., 2012). This influence is visible and acute when examining externalizing behavior (Brody, 2004; Kramer and Bank, 2005). Sibling relationships strongly affect sexual behavior (Kowal and Blinn-Pike, 2004; Tucker et al., 2001) and substance use (Samek et al., 2015a; 2015b; Slomkowski et al., 2001; 2005). It has been suggested that the sibling influence may even be stronger than parental influence (Pike et al., 2005). However, this influence may be more moderate than others have claimed (Poelen et al., 2009). The effect of sibling relationship on behavior is particularly difficult to measure because the relationship fluctuates in warmth throughout the lifetime (Sanders, 2004) and is susceptible to conflict in adolescence (Noller, 2005). Nonetheless, siblings seem to exert a unique, independent influence on each other during adolescence and emerging adulthood.

The sibling influence has been tied to deviant behavior. Several studies have found that warmth and closeness in sibling relationships increase the likelihood of substance use and sexual behaviors if one sibling already engages in such behavior (McHale et al., 2009; Slomkowski et al., 2005), but limits likelihood of deviant behavior if siblings don't engage (Samek et al., 2011). If one sibling exhibits aggressive behavior toward their sibling, this may also lead to externalizing problems (Natsuaki et al., 2009). Sibling perception has also been identified as a causal factor, as one study found that shared friends and admiration lead to deviant behavior (Whiteman et al., 2014). A wide variety of reasons may motivate an individual to engage in deviant behavior to begin with, but family literature has particularly emphasized poor monitoring by parents (Knafo et al., 2013) and family conflict (McQueen et al., 2003).

\section{Model to Be Tested}

The focus of the current study is to examine the influence a sibling relationship has on three distinct behavior outcomes. The outcomes are deviant behavior, sexual behavior and alcohol use. Figure 1 illustrates the model to be tested. The primary research question asked was whether the influence of sibling delinquency on respondent deviance, sexual behavior and alcohol use was moderated by sibling support and contact during emerging adulthood. 


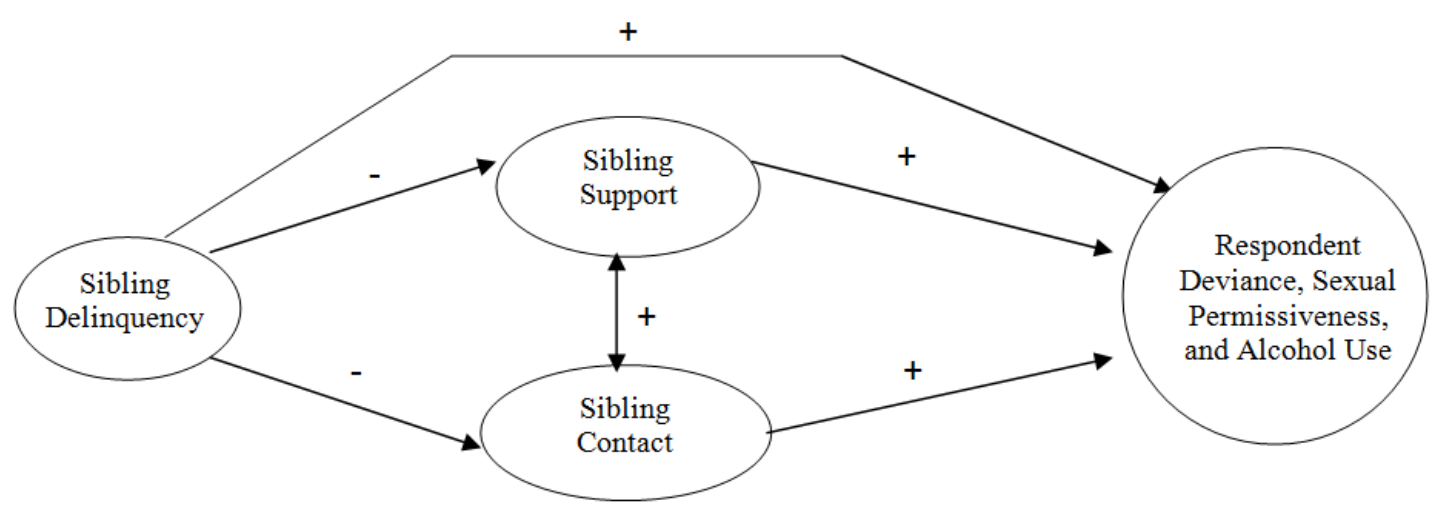

Fig. 1. Model testing the influence of sibling delinquency on respondent deviance, sexual behavior and alcohol use

\section{Explanation of Model}

First, it is expected that an individual who has a sibling that is delinquent would be more likely to be deviant themselves. Deviance is defined as behaviors that compromise the well-being of others (Bennett and Robinson, 2000). This pattern has been established for adolescents (Buist, 2010; Needle et al., 1986) and would be expected to be accurate for emerging adults. Using a social learning theory lens, the sibling relationship would be influential in providing a reference point in how to act as an adult. Through observation, siblings would teach one another what is acceptable behavior and help develop outcome expectancies (D'Amico and Fomme, 1997). There is a clear expectation that there would be an increase in respondent deviance when a sibling is delinquent.

Second, it is expected that overall closeness to a delinquent sibling would be lower (Brody, 1998) due to the observed negative feedback to a deviant individual. However, it would also be possible that siblings who are both engaging in risky behavior would have a close relationship. According to social learning theory, siblings who both engage in deviant behavior would be more likely to interact and influence one another than a sibling situation where one engages in deviant behavior and the other does not (Slomkowski et al., 2001; Solmeyer et al., 2014).

Next, it is expected that a delinquent sibling who gives or receives a high level of support to a respondent would be more likely to have a greater influence on them. Therefore, a greater level of support from a delinquent sibling would result in a greater level of deviance for the respondent. Also, there is a limited understanding of the type of support emerging adult siblings provide for one another. In response to Milevsky's (2005) recommendation to analyze how emerging adults interact with each other, this study assesses both emotional and instrumental support within this particular age group.

According to the model, it is expected that having a delinquent sibling will influence an individual's sexual permissiveness as well. It has been reported that emerging adults who engage in antisocial or deviant behaviors are more likely than others to engage in risky sexual behaviors and to get a sexually transmitted infection (Capaldi et al., 2002). Delinquent behavior of a sibling should positively influence respondent sexual behavior.

Sexual permissiveness was defined as when individuals believed it was acceptable to have intercourse with another person. Reporting when a person is willing to have sex is often an acknowledgment that, even though a person has no plans or intentions to engage in sexual behavior, one might if the circumstances are right (Gerrard et al., 2002). The willingness to participate in the behavior is predictive in the resulting behavior (Gibbons and Gerrard, 1995; 1997). The amount of support and contact siblings provide each other is also expected to influence the respondent's sexual behavior. Having a high level of support and contact with a delinquent sibling would influence the respondent's belief about when it is acceptable to have intercourse. This would result in more permissive attitudes and behavior regarding sexual activity.

It is also expected that delinquent sibling behavior would increase the likelihood that the respondent would participate in alcohol use. Having a sibling who uses substances has been found to be extremely influential in individual substance use (Avenevoli and Merikangas, 2003; Slomkowski et al., 2005). It is reasonable to expect that a similar association would be found in an emerging adult sample.

Social Learning Theory argues that behavior is primarily learned through observation and its consequences. Positive effects of behavior, such as recognition, accolades and power, inspire others to mimic such behavior (Bandura, 1977). This theory is particularly relevant to family life, especially in the parent-child and sibling relationship. Indeed, the amount of time family members spend together increases the opportunity for observation and effects of behavior. Furthermore, it increases opportunity to show warmth and support. Bandura argued that warm and close relationships conditions siblings to imitate behavior 
(Bandura and Walters, 1963). Social Learning Theory's emphasis on observation, imitation and family life make it particularly relevant framework for the current study.

\section{Methodology}

\section{Data Collection and Analysis}

Data was collected from 690 undergraduates enrolled in a mid-sized Midwestern state university during the 2005-2006 academic years. Participants were recruited from an introductory family relationships course and offered extra credit for their time. They completed a survey during regular course hours. Questions were formulated using a Likert scale format and focused on family of origin, current and past relationship experiences and attitudes and behaviors regarding sex, marriage, substance use and religion. Participation was voluntary and there were no identifiers on the survey instrument.

The total sample was comprised of 95 males and 595 females. The course from which participants are recruited tends to attract a majority of female students, which may explain why there is such a large amount of female participants compared to male participants. The majority of the participants were between the ages of 20 and $22(68.9 \%)$, with $25.8 \%$ being either 18 or 19 and nearly $6 \%$ being age $22-25$. Nearly $56 \%$ of the respondents state they grew up in the suburbs or city and $20.1 \%$ grew up in a town smaller than 30,000 people. Slightly more than $70 \%$ of the sample indicated that their parents were married to each other. Approximately 65\% of the sample had a family income over $\$ 80,000$. When asked to identify how many siblings they had, 309 respondents $(44.7 \%)$ indicated that they had one sibling, 201 (29.1\%) respondents had two siblings, 78 respondents (11.3\%) had three siblings and $50(7.2 \%)$ had four or more siblings. There were 52 (7.5\%) respondents that reported having no siblings. In total, there were 557 females and 81 males who had a sibling. Analyses were conducted for those respondents who indicated they had a sibling.

\section{Measures}

\section{Sibling Delinquency}

Sibling delinquency was measured with seven items that asked participants to "indicate how much they agree or disagree" with statements that assessed the delinquent behavior of their sibling closest in age. Focusing on one single sibling allowed for a better understanding of a specific sibling relationship rather than a general assessment of the entire sibling subsystem. Questions included topics about substance use, violating the law and general fighting or getting in trouble with the law. Responses ranged from 1 (strongly agree) to 5 (strongly disagree). The questions in the scale were selected to be similar to the questions asked about the respondent's deviant behavior and have been used in extant studies that focus on sibling delinquency (Gibbons and Gerrard, 1995). There were 164 of the respondents who indicated that their sibling had elevated levels of delinquent activity. Responses were reversed coded so that a high score indicated higher levels of delinquency. The scale had a Cronbach's alpha of 0.867 and a range of individual scores from 7 to 35 .

\section{Sibling Contact}

Respondents were asked with a single item about the level of contact they have had over the past 12 months with their sibling who is nearest in age to them. The definition of contact included interacting in the following ways: Face to face, exchange of letters or emails, or talking on the phone. Response choices were: Once a week, monthly, only on special occasions such as holidays or birthdays, less than once a year and never. This question was adapted from an item in the Health and Retirement Study (1994).

\section{Sibling Support}

Two items were used to capture sibling support. The first item asked about the level of emotional support and the second item assessed instrumental support. The questions were adapted from the Health and Retirement Study (1994). For emotional support, respondents were asked how often they have given or received emotional support from their sibling who was nearest in age to them over the past 12 months. Instrumental support was assessed by asking how often the respondent has given or received a favor such as a ride, help with schoolwork, or another type of favor, with the sibling. The scale had a Cronbach's alpha of 0.738 with a range of scores from 2 to 10 .

\section{Respondent Deviance}

An eleven item scale was used to assess how often, over the past 12 months, respondents participated in particular deviant behaviors. The scale that was used is Delbert S. Elliot's Delinquency Checklist (Elliot et al., $1985 ; 1986)$. The topics that were assessed were substance use, violating the law and general level of fighting and getting in to trouble. The scale had a Cronbach's alpha of 0.657 and the range of scores being from 11 to 55 .

\section{Sexual Permissiveness}

Six items were used to assess sexual behavior permissiveness. The items were adapted from previously validated questions regarding sexual permissiveness (Reiss and Lee, 1988) and have been used throughout the literature (Willetts et al., 2004). The first three items assessed how many persons the respondent has participated in genital, oral and anal intercourse with. 
Response categories ranged from none to 10 or more. The final three questions addressed when it would be acceptable to participate in genital, oral and anal sex. Response categories ranged from never to when dating casually. Responses were coded so that the higher number resulted in a more permissive response. The scale had a Cronbach's alpha of 0.808 .

\section{Respondent Alcohol Use}

The alcohol use variable was assessed by using two items. They were how often the respondent drank alcoholic beverages in a typical month and the amount of times a respondent drank more than 4 (female) or 5 (male) drinks in a single night. These items were based on the CDCP (2007) criteria for binge drinking. Response categories varied by item but generally the response categories ranged from never to 4-5 drinks in a single night. Similar to previous scales, the remaining response categories were coded to fit in logical order between 1 and 5 with the higher scores indicating higher level of alcohol use. The scale had a Cronbach's alpha of 0.907 and an individual score range from 2 to 10 .

\section{Analytic Strategy}

Gender has been shown to have a significant impact on sibling relationships (Cicirelli, 1995; Kim et al., 2007; Miner and Uhlenberg, 1997). For this study, 86\% percent of the total sample included a female respondent. Nonetheless, to better understand the role gender played in emerging adult sibling relationships, the data were analyzed separately by gender.

The first analysis tested the zero-order correlations of the variables in the model. The next analysis tested if there was a moderating effect between the variables. Baron and Kenny (1986) steps were followed when testing whether moderation occurred. The moderating analyses looked at the influence sibling support and sibling contact had on the relationship between sibling delinquency and the dependent variables. It was expected that when there was high sibling support and/or sibling contact between the respondent and their delinquent sibling, then the relationship between sibling delinquency and the dependent variables would be strong.

\section{Results}

The first analysis addressed the relationship between the study variables. Table 1 indicates the results.

It was expected that sibling delinquency would be positively correlated with the dependent variables (respondent deviance, respondent sexual permissiveness and respondent alcohol use). This expectation was found among females but not for males. Sibling delinquency significantly correlated with all the variables in the model for females. In addition, there was a negative correlation between the level of contact and the level of deviance among female respondents. One possibility for the different outcomes between the males and females was the result of the small sample size $(n=81)$ of males. The low sample size may not have allowed for enough power to detect differences between the variables.

It was expected that sibling support would be positively correlated with the dependent variables. This expectation was not supported for respondent deviance or respondent alcohol use, as the relationship between sibling support and sibling contact was not significantly associated with these dependent variables for males or females. However, there were some mixed findings with the association of support with respondent sexual permissiveness.

Sibling contact was positively correlated with female sexual permissiveness and sibling support was negatively correlated with male sexual permissiveness. Therefore, the correlations indicate that females who had a high level of contact with a delinquent sibling engaged in more risky sexual behavior. The male's sibling support was found to be negatively correlated with sexual permissiveness in that more sibling support resulted in a lower level of sexual permissiveness.

\section{Test of Moderation}

The second research question asked whether sibling support and sibling contact moderated the relationship between sibling delinquency and the dependent variables. The data were analyzed separately by gender and included participants that reported having a sibling. Only the female results will be presented as the male moderating relationships were not found to be significant. The hypothesized models were tested using regression analyses.

Table 1. Correlations among study variables

\begin{tabular}{|c|c|c|c|c|c|c|}
\hline Variable & 1 & 2 & 3 & 4 & 5 & 6 \\
\hline 1. Sibling Delinquency & - & $-0.176 * *$ & $-0.247 * *$ & $0.148 * *$ & $0.164 * *$ & $0.115 * *$ \\
\hline 2. Sibling Contact & 0.098 & - & $0.465 * *$ & 0.004 & 0.044 & $0.087^{*}$ \\
\hline 3. Sibling Support & -0.012 & $0.466 * *$ & - & 0.026 & 0.068 & -0.061 \\
\hline 4. Respondent Deviance & 0.053 & $0.186^{*}$ & -0.069 & - & $0.717 * *$ & $0.564 * *$ \\
\hline 5. Respondent Alcohol Use & 0.023 & 0.158 & -0.121 & $0.695 * *$ & - & $0.558 * *$ \\
\hline 6. Respondent Sexual Permissiveness & 0.161 & 0.002 & $-0.190 *$ & $0.439 * *$ & $0.512 * *$ & - \\
\hline
\end{tabular}

Note. Correlations for female respondents are presented above the diagonal; male respondents are presented below the diagonal. $* *=$ correlation is significant at $p<0.01$; *orrelation is significant at $p$ 
For each test of moderation there were four models analyzed. Analyzing four models allowed for a more comprehensive understanding of the influence the variables had on one another. The standardized coefficients, as well as the significance levels, are presented in the moderation tables. By way of explanation, there was a moderating effect when the interaction term (Sibling Delinquency x Sibling Support or Sibling Delinquency $\mathrm{x}$ Sibling Contact) was significant while the independent and moderating variables were included in the model. When the interaction term in Model 2 was significant, then sibling support was a moderator. When the interaction term in Model 3 was significant, then sibling contact was a moderator. Moderators that were found to be significant are graphed. Model 4 was a test of how all the variables in the analysis, including both interaction terms, interacted with each other.

As was expected, when each interaction term was stepped into the model separately, as in models 2 and 3 , each had a significant affect. Therefore, sibling support and sibling contact were moderators between sibling delinquency and respondent deviance for females. However, when both sibling support and sibling contact were included in the model only sibling support was significant. The results indicated that the more support an individual received from a delinquent sibling increased the influence of that delinquent sibling on the respondent's level of deviance. Figure 2 illustrates the moderating influence sibling support has on the relationship between sibling delinquent behavior and respondent deviance. The dashed regression line represents sibling support scores that were one standard deviation above the mean and the solid regression line represents scores that were one standard deviation below the mean.

For female respondents who had limited support with a delinquent sibling (one standard deviation below the mean) their own level of deviance was not associated with the increased level of sibling delinquency. However, when respondents had a high level of support from a delinquent sibling (one standard deviation above the mean) their own level of deviance increased substantially. Figure 3 illustrates the moderating influence sibling contact has on the relationship between sibling delinquency and respondent deviance.

Sibling contact had a similar impact on respondent deviance. Female respondents who had a low level of contact with a delinquent sibling did not see their own level of deviance influenced by the increased level of sibling delinquency. However, when respondents had a high level of contact with a sibling their own level of deviance increased as the level of delinquency from their sibling increased. The same moderating tests were applied to male respondents and the results are presented in Table 3.

\section{Respondent Sexual Permissiveness}

Respondent sexual permissiveness was the second outcome variable to be analyzed. The sexual permissiveness scale had a maximum score of 24 with higher scores indicating an increased level of permissiveness. Female participants reported a mean sexual permissiveness score of 9.31 and a standard deviation of 4.86. Male participants were slightly more permissiveness than females as they reported a mean sexual permissiveness score of 11.12 and a standard deviation of 2.73. Though males, on average, reported more permissiveness than females, there was more variability in female sexual permissiveness scores than there was for males as is illustrated by the standard deviations. Therefore, males appear to be more predictable in their sexual behavior and sexual beliefs than females.

Table 2. Regression of the moderating effects on respondent deviance and sibling delinquency

\begin{tabular}{lllll}
\hline Explanatory Variable & Model 1 & Model 2 & Model 3 & Model 4 \\
\hline Sib. Delinquency & $0.108^{* *}$ & $-0.268^{* *}$ & $-0.500^{* *}$ & $-0.497^{* *}$ \\
Sib. Support & -0.007 & $-0.764^{* *}$ & -0.058 & $-0.563^{* *}$ \\
Sib. Contact & -0.007 & 0.216 & $-1.488^{* *}$ & -0.796 \\
Sib. Dev. x support & - & $0.057^{* *}$ & - & $0.040^{*}$ \\
Sib. Dev. x contact & - & - & $0.142^{* *}$ & 0.080 \\
\hline
\end{tabular}

Note. ${ }^{* *}=$ correlation is significant at $p<0.01,{ }^{*}=$ correlation is significant at $p<0.05$

Table 3. Regression of the moderating effects on respondent deviance and sibling delinquency

\begin{tabular}{lllll}
\hline Explanatory Variable & Model 1 & Model 2 & Model 3 & Model 4 \\
\hline Sib. Delinquency & 0.019 & -0.013 & -0.288 & -0.443 \\
Sib. Support & -0.523 & -0.588 & -0.564 & -0.277 \\
Sib. Contact & $1.800^{*}$ & $1.796^{*}$ & 1.094 & 0.392 \\
Sib. Dev. x support & & 0.005 & & -0.025 \\
Sib. Dev. x contact & & & 0.069 & 0.141 \\
\hline
\end{tabular}

Note. ${ }^{*}=$ correlation is significant at $p<0.05$ 
Table 4. Regression of the moderating effects on respondent sexual permissiveness and sibling delinquency (females)

\begin{tabular}{lllll}
\hline Explanatory Variable & Model 1 & Model 2 & Model 3 & Model 4 \\
\hline Sib. Delinquency & 0.078 & -0.176 & $-0.309^{*}$ & -0.309 \\
Sib. Support & -0.018 & $-0.531^{*}$ & -0.052 & -0.413 \\
Sib. Contact & -0.355 & -0.377 & $-1.467^{*}$ & -0.947 \\
Sib. Dev. x support & & $0.039^{*}$ & & $0.091^{*}$ \\
Sib. Dev. x contact & & & & 0.047 \\
\hline
\end{tabular}

Note. ${ }^{*}=$ correlation is significant at $p<0.05$

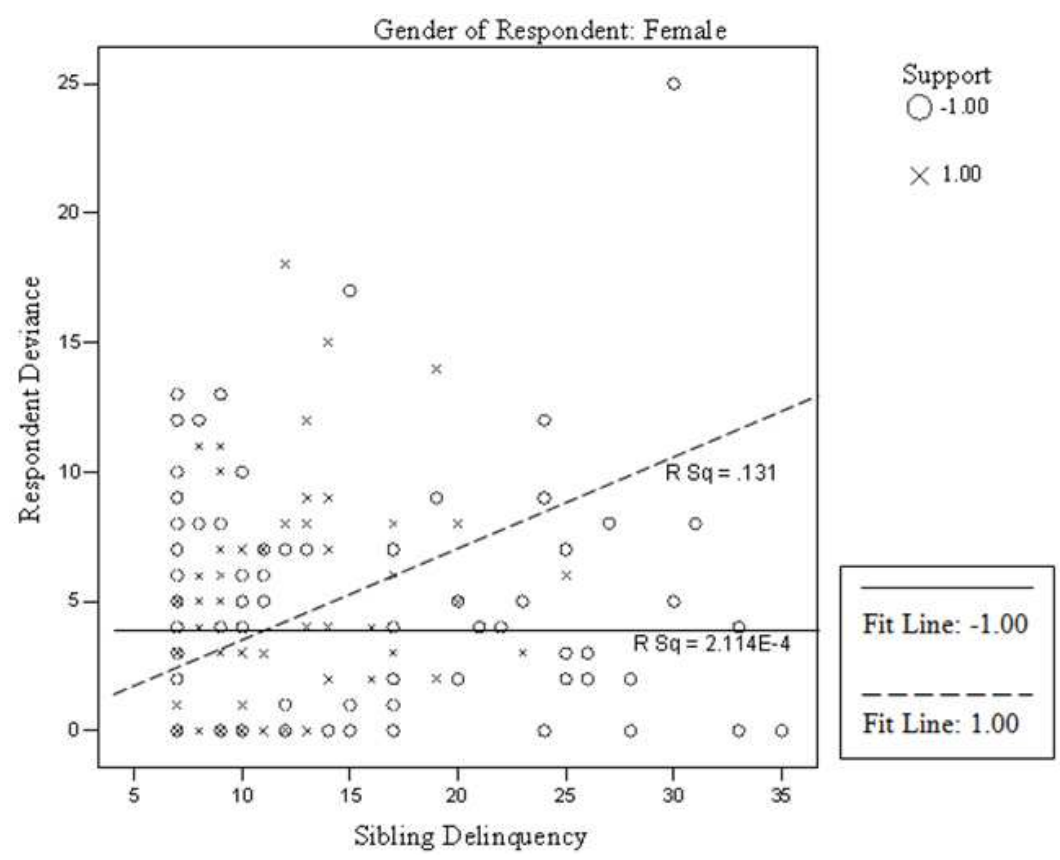

Fig. 2. Moderating effect of sibling contact on sibling delinquency and respondent deviance

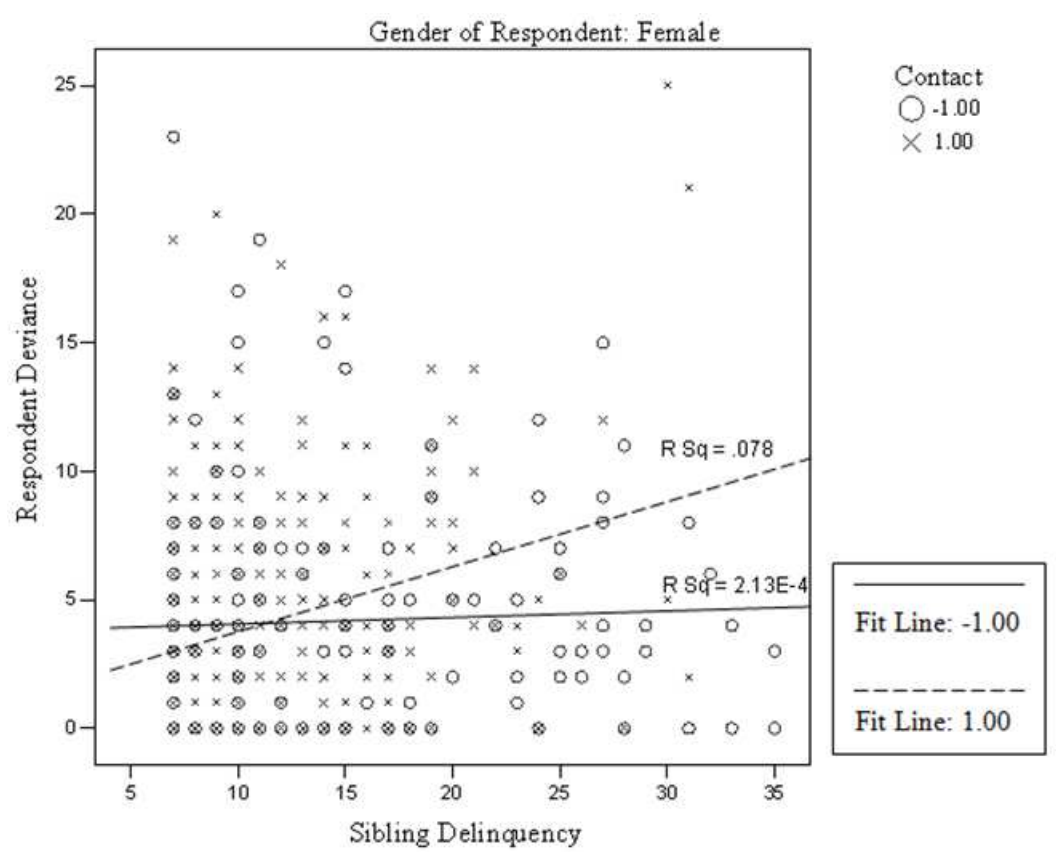

Fig. 3. Moderating effect of sibling contact on sibling delinquency and respondent deviance 


\section{Test of Moderation}

Once again, there were four models that were tested in the moderation analyses. Table 4 reports on the results for the test of moderation of sibling support and sibling contact on the relationship between sibling delinquency and respondent sexual permissiveness.

The interaction term for both sibling support and sibling contact were significant at the $p=0.05$ level for females when they were stepped into the model separately. As was expected, both sibling support and sibling contact moderated the relationship between sibling delinquency and respondent sexual permissiveness. Similar to respondent deviance, when all interaction terms were included in the analysis (Model 4) the results were no longer significant, this may be due to multicolinearity. Nevertheless, results for the significant interactions were graphed in order to establish that the relationship between variables was in the expected direction. Figure 3 illustrates the moderating effect of sibling support for females.

Figure 4 illustrates there was an increased likelihood of respondents being more sexually permissive when the level of sibling delinquency increased and the level of support of the deviant sibling increased. Figure 5 illustrates the moderating effect of sibling contact on the relationship between sibling delinquency and respondent sexual permissiveness.

Figure 5 illustrates that sibling deviance did not result in respondent sexual permissiveness for females that have a low level of contact with a delinquent sibling, but there was an increased likelihood of respondents being more sexually permissive when the level of sibling delinquency increased and the level of contact with the delinquent sibling increased. The same tests were applied to males in the sample and their results are in Table 5.

Table 5. Regression of the moderating effects on respondent sexual permissiveness and sibling delinquency

\begin{tabular}{lllll}
\hline Explanatory variable & Model 1 & Model 2 & Model 3 & Model 4 \\
\hline Sib. Delinquency & 0.128 & -0.218 & -0.571 & -0.263 \\
Sib. Support & -0.580 & $-1.291^{*}$ & $-0.670^{*}$ & -1.258 \\
Sib. Contact & 0.644 & 0.599 & 0.978 & 0.449 \\
Sib. Dev. x support & & 0.055 & 0.159 & 0.052 \\
Sib. Dev. x contact & & & & 0.015 \\
\hline
\end{tabular}

Note. ${ }^{*}=$ correlation is significant at $p<0.05$

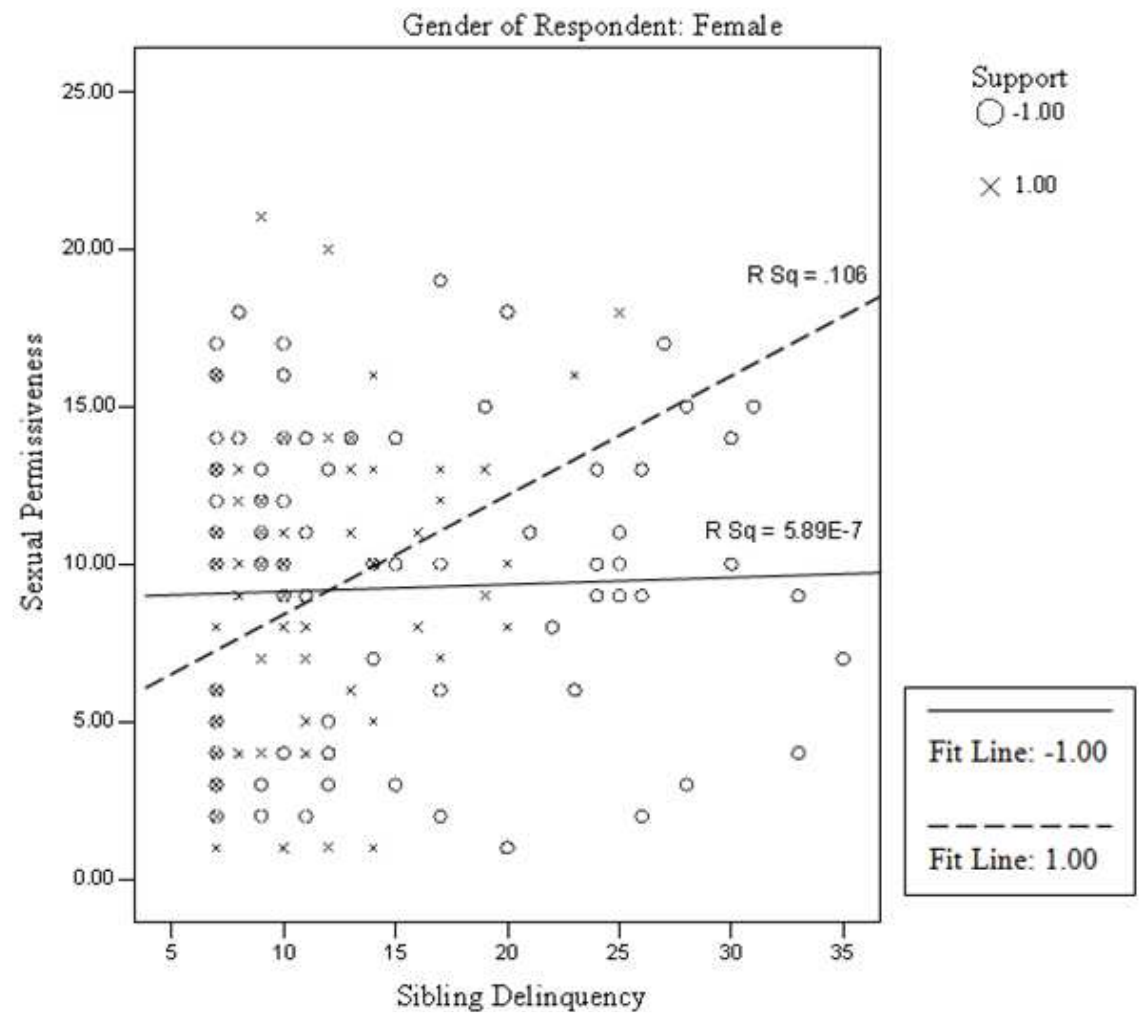

Fig. 4. Moderating effect of sibling contact on sibling delinquency and sexual permissiveness 


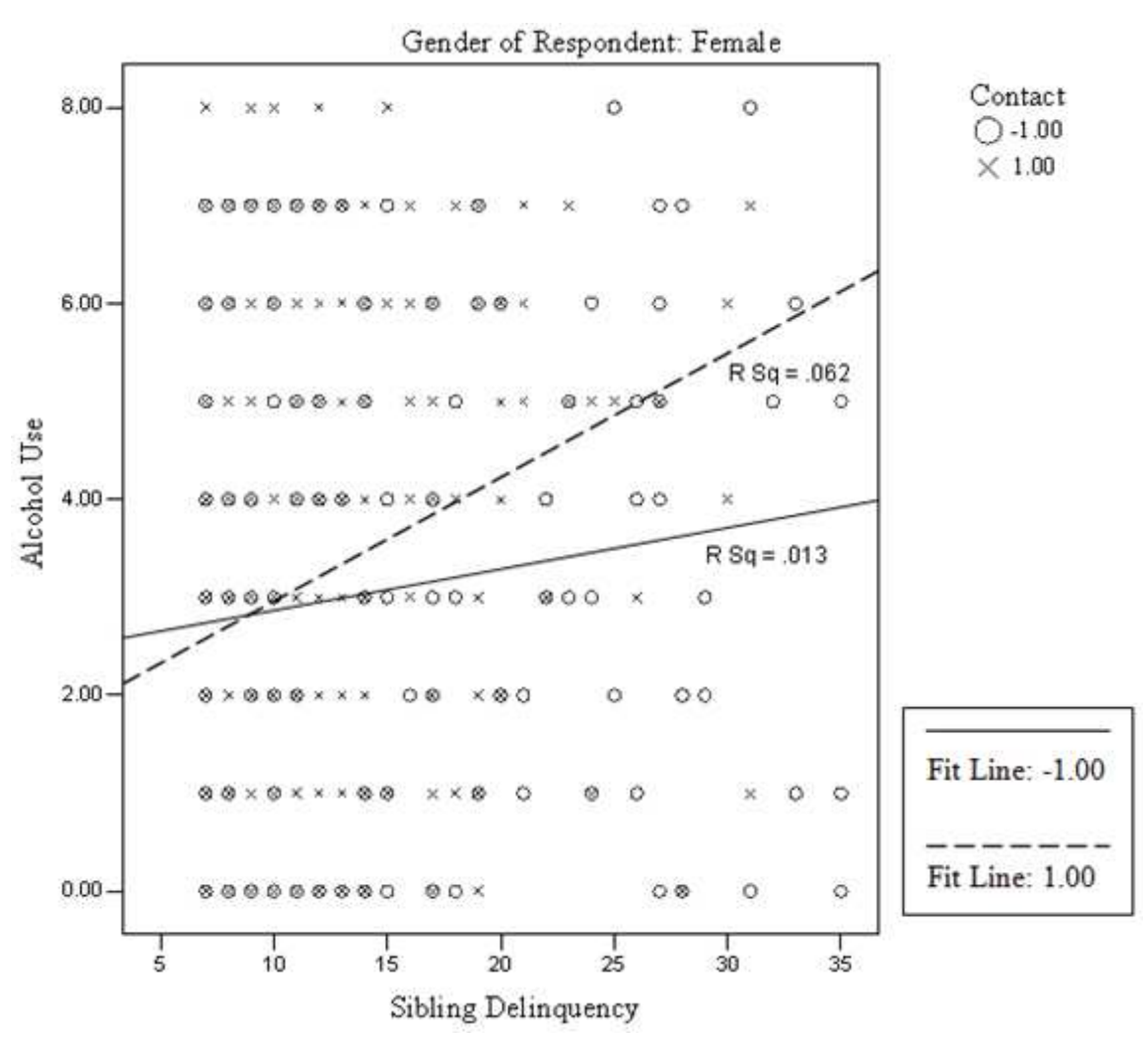

Fig. 5. Moderating effect of sibling support on sibling delinquency and alcohol use

Sibling support and sibling contact were not found to be moderators between sibling delinquency and respondent sexual permissiveness for males as the interaction term was not significant in the model analysis. Based on theory and past research, it was expected that there would be a significant moderating effect on males as well as females. However, this relationship was not found. Alcohol use was the final dependent variable that was tested.

\section{Respondent Alcohol Use}

The final outcome variable analyzed was respondent alcohol use. The alcohol use scale had a maximum score of 8 with higher scores indicating an increased level of alcohol use. Female participants reported a mean alcohol use score of 3.08 and a standard deviation of 2.46. Male participants reported a mean alcohol use score of 3.59 and a standard deviation of 2.73 .

\section{Test of Moderation}

It was expected that both support and contact would have a moderating effect on the relationship between sibling delinquency and respondent alcohol use. Table 6 presents the results for the female test of moderation of sibling support and sibling contact between sibling delinquency and respondent alcohol use.
When the interaction term for sibling support was stepped into the model (Model 2) separately it was significant. The same is true for the interaction term for sibling contact. However, as has occurred in the previous moderation analyses, when both interaction terms are included in the model only one of the interaction terms was significant. The Model 4 analysis of alcohol use indicated that the sibling contact interaction term was significant but the sibling support interaction was no longer significant with a. This may be due to multicolinearity. Results for the significant interactions were graphed in order to illustrate that the relationship between variables was in the expected direction. Figure 5 illustrates the effect of sibling support on the relationship between sibling delinquency and respondent alcohol use.

Figure 5 illustrates that the level of sibling delinquency increased the risk of alcohol use by females regardless of the level of sibling support. However, the relationship between sibling delinquency and respondent alcohol use was stronger when support from the sibling was high. Figure 6 illustrates a similar effect for sibling contact for females.

Figure 6 illustrates that alcohol use for females increased regardless of level of contact with a delinquent sibling. Similar to the findings for support, there was an increased likelihood of respondents engaging in higher 
levels of alcohol use when there was an increased level of contact with a delinquent sibling. The moderating relationship of sibling support and contact was also tested with male respondents. Table 7 represents the analyses results for males.

It was expected that sibling support and contact would also moderate the relationship between sibling delinquency and responded alcohol use for males. However, once again, the results indicated that neither support nor contact were moderators for males as the interaction terms were not significant in the models tested. It was expected that there would be a significant moderating impact on both males and females, but a moderating influence was not found for males.

Table 6. Regression of the moderating effects on respondent alcohol use and sibling delinquency

\begin{tabular}{lllll}
\hline Explanatory Variable & Model 1 & Model 2 & Model 3 & Model 4 \\
\hline Sib. Delinquency & $0.065^{* *}$ & -0.076 & $-0.224^{*}$ & $-0.224^{*}$ \\
Sib. Support & -0.114 & $-0.400^{* *}$ & $-0.138^{*}$ & $-0.268^{*}$ \\
Sib. Contact & $0.355^{* *}$ & $0.343^{*}$ & -0.482 & -0.292 \\
Sib. Dev. x support & & $0.022^{* *}$ & $0.068^{* *}$ & 0.010 \\
Sib. Dev. x contact & & & $0.052^{*}$ \\
\hline
\end{tabular}

Note. ${ }^{* *}=$ correlation is significant at $p<0.01, *=$ correlation is significant at $p<0.05$

Table 7. Regression of the moderating effects on respondent alcohol use and sibling delinquency

\begin{tabular}{lllll}
\hline Explanatory Variable & Model 1 & Model 2 & Model 3 & Model 4 \\
\hline Sib. Delinquency & -0.005 & 0.011 & 0.107 & 0.153 \\
Sib. Support & $-0.317^{*}$ & -0.285 & -0.303 & -0.390 \\
Sib. Contact & $0.877^{*}$ & $0.879^{*}$ & 1.139 & 1.351 \\
Sib. Dev. x support & & -0.002 & -0.025 & 0.008 \\
Sib. Dev. x contact & & & & -0.047 \\
\hline
\end{tabular}

Note. ${ }^{*}=$ correlation is significant at $p<0.05$

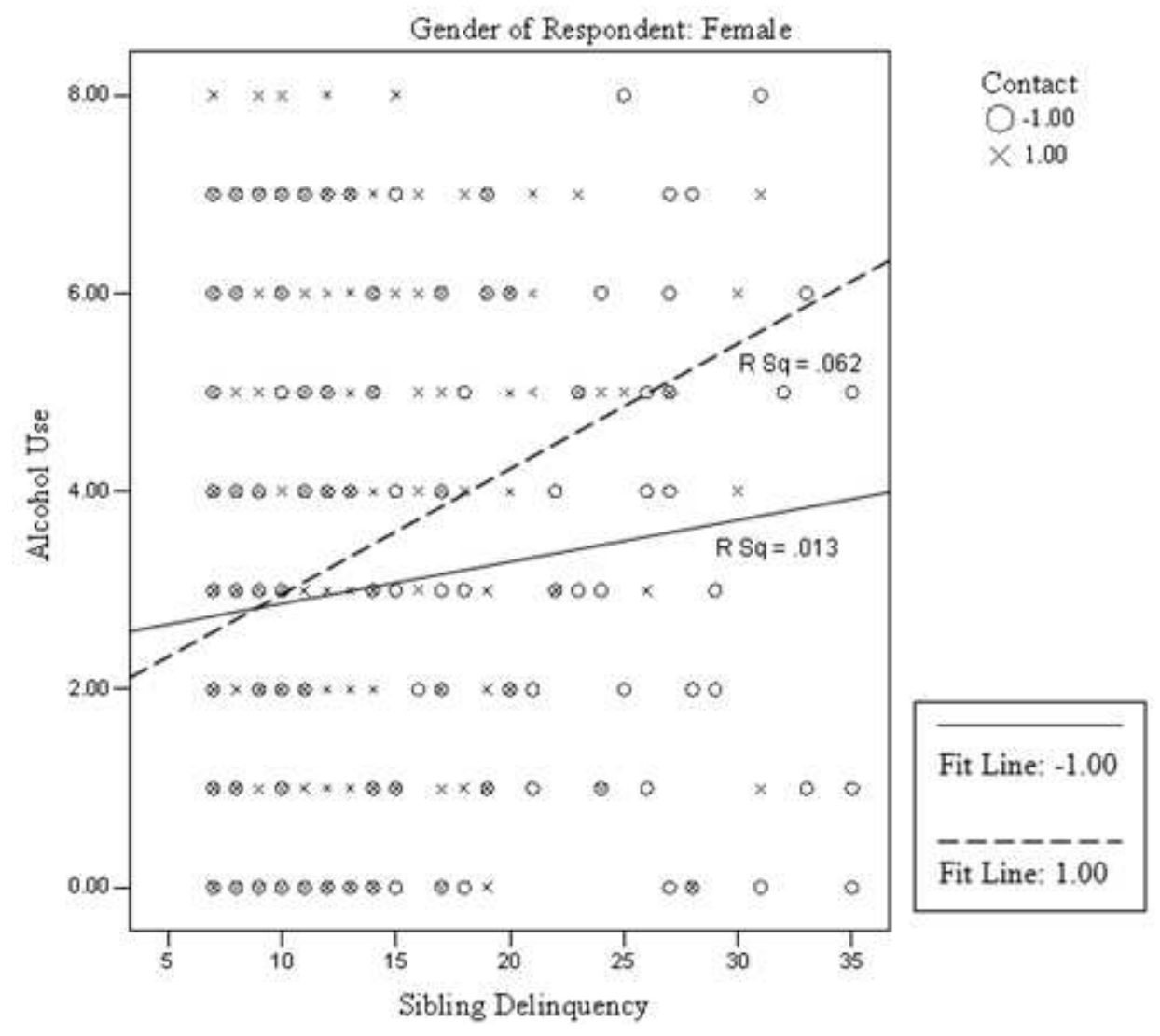

Fig. 6. Moderating effect of sibling contact on sibling delinquency and alcohol use 
The overall results of the moderating effects were mixed. It was expected that the analyses for males would result in significant moderating effects but that was not found. However, the results were much different for the female respondents. A strong moderating effect of sibling support and sibling contact on the relationship between sibling delinquency and all the dependent variables was found.

\section{Discussion}

The goal of the current study was to examine the influence sibling support and sibling contact have on an emerging adult's deviant behavior, sexual permissiveness and alcohol use. The influence siblings have on externalizing behavior during emerging adulthood was examined by testing the moderating effects sibling support and sibling contact have on an individuals' externalizing behavior. The results indicated that sibling support and sibling contact moderated the association between sibling delinquency and respondent externalizing symptoms for females but not for males. This association was found to be stronger among siblings with a greater amount of contact and support from a delinquent sibling.

An important finding in this study was that the relationship between sibling deviance and respondent externalizing behavior was moderated by both sibling support and sibling contact for females. This link was stronger when the relationship quality was higher. That is, a delinquent sibling significantly impacted the respondent's deviant behavior, sexual permissiveness and alcohol use with more frequent support and contact resulting in more risky behavior. This finding was consistent with previous studies which have addressed the influence siblings have on externalizing behavior (Brody et al., 2004). Previous extant research has found this connection when examining childhood and adolescent sibling influence, but the current study extends the previous research to include emerging adults.

In order to further understand the impact sibling contact and sibling support have on externalizing behavior it would be important to know the specific mechanisms by which the greater the sibling relationship quality results in similar externalizing behavior. This study does not address these specific mechanisms but it does indicate several possible explanations. For example, emerging adults who believe they have support from a sibling probably would spend an increased amount of time with them. It could be assumed that the increased level of contact and support from a delinquent sibling would result in a greater opportunity to influence behavior. Siblings, therefore, could become "partners in crime" (Rowe and Gulley, 1992). This explanation would be consistent with previous studies that have used a social learning perspective to study sibling influence during childhood and adolescence (Watt et al., 2004).

Gender in sibling relationships has been documented to have important ramifications for emerging adult (Killoren et al., 2015) and throughout the life course (Cicirelli, 1995). The results from this study demonstrated that the moderating effects of sibling support and sibling contact were only found among female participant. Based on theory and previous research, it was expected that both females and males would be significantly influenced by the moderating variables. It is believed that the small sample size for male respondents $(\mathrm{n}=81)$ contributed to the nonsignificant results. Based on the statistical trends observed in the results, it is believed that sibling contact and sibling support would have had the same moderating effects for males as were observed with females with a larger sample size.

Gender did not affect the amount of contact and support siblings received in the sample. The results indicated that sibling contact and sibling support were similar for both male and female respondents. This finding is similar to Scharf et al. (2005) finding that sibling relationship quality was not impacted based on gender. This is in contrast to some of the previous studies that reported that gender was related to the quality of the sibling relationship during childhood and adolescence (Buhrmester and Furman, 1990). Further examination is needed to better understand why gender may not be as important a factor during emerging adulthood when compared to other life stages.

Several dependent variables were examined in this study, but alcohol use had some unique characteristics that warrant further discussion. When examining the respondent deviance scale responses, both males and females reported a high level of participation in drunk driving and public drunkenness. It has been reported that there is a significant escalation of alcohol use during emerging adulthood (Martin and White, 2005), with the highest rate of alcohol use occurring among 18 to 20 year olds. In the current sample, alcohol use was prevalent regardless of age and use increased regardless of how much support and contact they reported from a delinquent sibling. However, when there was support and contact from a delinquent sibling the level of alcohol use increased at a much faster rate. The continual rise in alcohol use during emerging adulthood warrants further examination. Alcohol use during emerging adulthood may be one externalizing behavior that may be more independent than deviant behavior and sexual permissiveness because alcohol use increased even when support and/or contact with a delinquent sibling was low.

Based on the high rates of risky alcohol consumption during emerging adulthood, particularly for college students, further understanding of alcohol use is needed. Peers have been found to be the primary influence for 
alcohol use during this time period but it has also been recommended that it is important to distinguish between various types of social influences (Read et al., 2005).

The present study was not designed to determine how individuals develop proneness to participation in risky behavior. However, the results have heuristic value on this issue. Siblings had more similar risky behavior when one sibling had a higher level of delinquency and the other sibling had increased support and a higher level of contact. Therefore, the sibling relationship provided an influence toward similar negative externalizing behavior as a delinquent sibling. Future research is needed to identify the amount of influence siblings provide during emerging adulthood when controlling for additional environmental influences such as parents, peers and neighborhood.

This study identified the moderating impact siblings have on negative externalizing behavior during emerging adulthood. The development of risky or delinquent behavior usually begins in the early years by an individual associating with those that are delinquent (Shortt et al., 2003). Without intervention, the negative behavior is likely to continue from one developmental period to another. Peer education and family involvement are often used to deter excessive or illegal alcohol use and risky sexual behavior. However, the sibling relationship could be an avenue to reduce potential risk during emerging adulthood. The findings of the study present important implications for practice: (1) Attention to sibling relationships should not end once an individual reaches emerging adulthood. Siblings continue to exert influence during this time which may in turn encourage deviant behavior, (2) emerging adults are particularly prone to dangerous alcohol use and should receive adequate information and support during this time to help them make informed decisions and (3) interventions for deviant behavior by therapists or social workers should include considerations of siblings to gauge their role and influence, as it may paint a more accurate picture of someone's initial introduction to deviant behavior and motivation.

\section{Limitations}

There were limitations to this study. First, the data were collected from a convenience sample as participants were recruited from undergraduate college classes. Therefore, the results only represent the population from which it was drawn and is not generalizable to the population at large. The data is also cross-sectional so we are unable to predict changes over time. It provides a snapshot of the participant's current relationship quality and behavior. The data were also generated from self-reports and involve retrospective recollections of past events.
Further, one of the primary components to the current study was assessing the power and influence of the sibling relationship. Sibling relationship quality was assessed through the level of contact and the level of support. Contact was measured with a single item and support was measured by two items. It is believed the questions used to assess sibling contact and sibling support provided a global assessment of the sibling relationship. Future research should add to these constructs by using a more comprehensive assessment of sibling relationship quality.

Finally, this sample did not specifically address sexual orientation. Sexual orientation has been found to be an important factor when studying family relationships. Future research should address how sexual orientation impacts the study variables.

\section{Conclusion}

To conclude, perhaps one of the most important lessons to be learned from this study is that sibling relationships are influential during emerging adulthood. Siblings can be an important source of support for each other and thereby influence each other's externalizing behavior. In the process of gaining autonomy and differentiating from the parental sub-system, emerging adults may seek help and understanding from their siblings and thereby become important role models for each other.

The results of this study augment the limited research that exists on sibling relationships during emerging adulthood. This study provided further explanation and insight into how the sibling relationship influences behavioral choices for emerging adults but there is much more to learn. Future research could further highlight how relationships with siblings are embedded within the behavioral choices individuals make with regard to self and close others.

\section{Acknowledgment}

Thank you for a great research team and supportive University.

\section{Author's Contributions}

F. Ryan Peterson: Proposed the data collection, collected the data, analyzed the data, wrote the paper and submitted the paper for publication.

Lesie Gordon Simons: Proposed the date collection, analyzed the data, and edited the paper.

Adriatik Likcani: Wrote the paper and submitted the paper for publicaiton.

Katherine Hickey: Edited the paper and submitted the paper for publication. 


\section{Ethics}

Data was collected after IRB approval.

\section{References}

Arnett, J.J., 2014. Emerging Adulthood: The Winding Road from the Late Teens through the Twenties. 2nd Edn., Oxford University Press, New York, ISBN-10: 0190209585, pp: 288.

Arnett, J.J., 2000. Emerging adulthood: A theory of development from the late teens through the twenties. Am. Psychol., 55: 469-480.

DOI: $10.1037 / / 0003-066 X .55 .5 .469$

Arnett, J.J. and J.L. Tanner, 2006. Emerging adults in America: Coming of age in the 21st Century. 1st Edn., American Psychological Association Press, Washington, D.C., ISBN-10: 1591473292, pp: 341.

Avenevoli, S. and K.R. Merikangas, 2003. Familial influences on adolescent smoking. Addiction, 98: 1-20. DOI: 10.1046/j.1360-0443.98.s1.2.x

Bandura, A., 1977. Social Learning Theory. 2nd Edn., Prentice Hall, Englewood Cliffs, ISBN-10: 0138167516, pp: 247.

Bandura, A. and R.H. Walters, 1963. Social Learning and Personality Development. 1st Edn., Holt, Rinehart and Winston, New York,

ISBN-10: 0030171407, pp: 329.

Baron, R.M. and D.A. Kenny, 1986. The moderatormediator variable distinction in social psychological research: Conceptual, strategic and statistical considerations. J. Personality Soc. Psychol., 51: 1173-1182. DOI: 10.1037/0022-3514.51.6.1173

Bennett, R.J. and S.L. Robinson, 2000. Development of a measure of workplace deviance. J. Applied Psychol., 85: 349-360. DOI: 10.1037/0021-9010.85.3.349

Brody, G.H., 1998. Sibling relationship quality: Its causes and consequences. Ann. Rev. Psychol., 49: 1-24. DOI: 10.1146/annurev.psych.49.1.1

Brody, G.H., 2004. Siblings' direct and indirect contributions to child development. Curr. Direct. Psychol. Sci., 13: 124-126.

DOI: $10.1111 /$ j.0963-7214.2004.00289.x

Brody, G.H., S. Kim, V.M. Murray and A.C. Brown, 2005. Longitudinal links among parenting, self-presentations to peers and the development of externalizing and internalizing symptoms in African American siblings. Dev. Psychopathol., 17: 185-205.

DOI: $10.1017 / \mathrm{S} 0954579405050108$

Buhrmester, D. and W. Fruman, 1990. Perceptions of sibling relationships during middle childhood and adolescence. Child Dev., 61: 1387-1398. DOI: $10.2307 / 1130750$

Buist, K.L., 2010. Sibling relationship quality and adolescent delinquency: A latent growth curve approach. J. Family Psychol., 24: 400-410.

DOI: $10.1037 / \mathrm{a} 0020351$
Capaldi, D.M., M. Stoolmiller, S. Clark and L.D. Owen, 2002. Heterosexual risk behaviors in at-risk young men from early adolescence to young adulthood: prevalence, prediction and association with STD contraction. Dev. Psychol., 38: 394-406.

PMID: 12005382

CDCP, 2007. Alcohol: Frequently asked questions. Centers of Disease Control and Prevention, Atlanta, GA.

Cicirelli, V.G., 1995. Sibling Relationships across the Life Span. 1st Edn., Plenum, New York, ISBN-10: 0306450259, pp: 255.

D'Amico, E.J. and K. Fromme, 1997. Health risk behaviors of adolescent and young adult siblings. Health Psychol., 16: 426-432. PMID: 9302539

Dunn, J., 2005. Commentary: Siblings in their families. J. Family Psychol., 19: 654-657.

DOI: $10.1037 / 0893-3200.19 .4 .654$

Elliot, D.S., D. Huizinga and S.S. Ageton, 1985. Explaining Delinquency and Drug use. 2nd Edn., Sage, Beverly Hills, CA., ISBN-10: 0803924046, pp: 176.

Elliot, D.S., D. Huizinga and S. Menard, 1986. Multiple-Problem Youth: Delinquency, Substance use and Mental Health Problems. 1st Edn., Springer, New York.

Feinberg, M.E., A.R. Solmeyer, M.L. Hostetler, K.L. Sakuma and D. Jones et al., 2013. Siblings are special: Initial test of a new approach for preventing youth behavior problems. J. Adolescent Health, 53: 166-173. DOI: 10.1016/j.jadohealth.2012.10.004

Gerrard, M., F.X. Gibbons, M. Reis-Bergan, L. Trudau and L.S. Vande Lune et al., 2002. Inhibitory effects of drinker and nondrinker prototypes on adolescent Salcohol consumption. Health Psychol., 21: 601-609. PMID: 12433013

Gibbons, R.X. and M. Gerrard, 1995. Predicting young adults' health risk behavior. J. Personality Soc. Psychol., 69: 505-517. PMID: 7562392

Gibbons, R.X. and M. Gerrard, 1997. Health Images and their Effects on Health Behavior. In: Health, Coping and Well-Being: Perspectives from Social Comparison theory, Buunk, B.P. and F.X. Gibbons (Eds.), Erlbaum, Mahwah, NJ., pp: 63-94.

Killoren, S.E., L.A. Wheeler, K.A. Updegraff, S.A. Rodriguez De Jesus and S.M. McHale, 2015. Longitudinal associations among parental acceptance, familism values and sibling intimacy in Mexicanorigin families. Family Process, 54: 217-231. DOI: 10.1111/famp.12126

Keeton, C., P. Teetsel, R. Dull and N. Ginsburg, 2015. Parent psychopathology and children's psychological health: Moderation by sibling relationship dimensions. J. Abnormal Child Psychol., 43: 1333-1342.

DOI: $10.1007 / \mathrm{s} 10802-015-0013-\mathrm{z}$ 
Kim, J.Y., S.M. McHale, A.C. Crouter and D.W. Osgood, 2007. Longitudinal linkages between sibling relationship and adjustment from middle childhood through adolescence. Dev. Psychol., 43: 960-973. DOI: 10.1037/0012-1649.43.4.960

Knafo, A., S. Jaffee, J. Neiderhiser, K. Marceau and D. Reiss, 2013. Four factors for the initiation of substance use by young adulthood: A 10-year follow-up twin and sibling study of marital conflict, monitoring, siblings and peers. Dev. Psychopathol., 25: 133-149. DOI: 10.1017/S0954579412000958

Kowal, A. and L. Blinn-Pike, 2004. Sibling influences on adolescents' attitudes toward safe sex practices. Family Relat., 53: 377-384.

DOI: 10.1111/j.0197-6664.2004.00044.x

Kramer, L. and L. Bank, 2005. Sibling relationship contributions to individual and family well-being: Introduction to the special issue. J. Family Psychol., 4: 483-485. DOI: 10.1037/0893-3200.19.4.483

Martin, S.E. and H.R. White, 2005. Still at risk for substance abuse; Transitions, risks and opportunitiesfor prevention of drug abuse during emerging adulthood: Introduction. J. Drug Issues, 35: 229-234. DOI: 10.1177/002204260503500201

McGue, M., A. Sharma and P. Benson, 1996. Parent and sibling influences on adolescent alcohol use and misuse: Evidence from a U.S. adoption cohort. J. Stud. Alcohol, 57: 8-18. DOI: $10.15288 /$ jsa. 1996.57 .8

McHale, S.M., K.A. Updegraff, H. Helms Erickson and A.C. Crouter, 2001. Sibling influences on gender development in middle childhood and early adolescence: A longitudinal study. Dev. Psychopathol., 37: 115-125.

DOI: $10.1037 / 0012-1649.43 .4 .960$

McHale, S.M., J. Bissell and J. Kim, 2009. Sibling relationship, family and genetic factors in sibling similarity in sexual risk. J. Family Psychol., 23: 562-572. DOI: $10.1037 / \mathrm{a} 0014982$

McHale, S.M., K.A. Updegraff and S.D. Whiteman, 2012. Sibling relationships and influences in childhood and adolescence. J. Marriage Family, 74: 913-930. DOI: 10.1111/j.1741-3737.2012.01011.x

McQueen, A., J. Greg Getz and J. Bray, 2003. Acculturation, substance use and deviant behavior: Examining separation and family conflict as mediators. Child Dev., 74: 1737-1750. DOI: 10.1046/j.1467-8624.2003.00635.x

Milevsky, A., 2005. Familial and contextual variables and the nature of sibling relationships in emerging adulthood. Marriage Family Rev., 37: 123-141. DOI: 10.1300/J002v37n04_07

Miner, S. and P. Uhlenberg, 1997. Intragenerational proximity and the social role of sibling neighbors after midlife. Family Relat., 46: 145-153.

DOI: $10.2307 / 585038$
Natsuaki, M., X. Ge, D. Reiss, J. Neiderhiser and C. García Coll, 2009. Aggressive behavior between siblings and the development of externalizing problems: Evidence from a genetically sensitive study. Dev. Psychol., 45: 1009-1018.

DOI: $10.1037 / \mathrm{a} 0015698$

Needle, R., H. McCubbin, M. Wilson, R. Reineck and A. Lazar et al., 1986. Interpersonal influences in adolescent drug use: The role of older siblings, parents and peers. Int. J. Addict., 21: 739-766. DOI: $10.3109 / 10826088609027390$

Noller, P., 2005. Sibling relationships in adolescence: Learning and growing together. Personal Relat., 12: 1-22. DOI: 10.1111/j.1350-4126.2005.00099.x

Pike, A., J. Caldwell and J.F. Dunn, 2005. Sibling relationships in early/middle childhood: Links with individual adjustment. J. Family Psychol., 19: 523-532. DOI: $10.1037 / 0893-3200.19 .4 .523$

Poelen, E.P., R.E. Engels, R.J. Scholte, D.I. Boomsma and G. Willemsen, 2009. Predictors of problem drinking in adolescence and young adulthood. Eur. Child Adolescent Psychiatry, 18: 345-352.

DOI: $10.1007 / \mathrm{s} 00787-009-0736-\mathrm{x}$

Read, J., M.D. Wood and C.A. Capone, 2005. A prospective investigation of relations between social influences and alcohol involvement during the transition into college. J. Stud. Alcohol, 66: 23-34. DOI: $10.15288 /$ jsa.2005.66.23

Reiss, I.L. and G.R. Lee, 1988. Family Systems in America. 4th Edn., Holt, Rinehart and Winston, New York, ISBN-10: 0030711134, pp: 512.

Rowan, Z., 2016. Social risk factors of black and white adolescents' substance use: The differential role of siblings and best friends. J. Youth Adolescence, 45: 1482-1496. DOI: 10.1007/s10964-016-0473-7

Rowe, D.C. and B.L. Gulley, 1992. Sibling effects on substance use and delinquency. Criminology, 30: 217-233. DOI: 10.1111/j.1745-9125.1992.tb01103.x

Samek, K.R., M. McGue, M. Keyes and W.G. Iacono, 2015a. Sibling facilitation mediates the association between older and younger sibling alcohol use in late adolescence. J. Rese. Adolescence, 25: 638-651. DOI: 10.1111 /jora.12154

Samek, D.R., M. Rueter, M.A. Keyes, M. McGue and W.G. Iacono, 2015b. Parent involvement, sibling companionship and adolescent substance use: A longitudinal, genetically informed design. J. Family Psychol., 29: 614-613. DOI: 10.1037/fam0000097

Samek, D., M. Rueter and N.J. Kaslow, 2011. Considerations of elder sibling closeness in predicting younger sibling substance use: Social learning versus social bonding explanations. J. Family Psychol., 25: 931-941. DOI: 10.1037/a0025857 
Sanders, R., 2004. Sibling Relationships: Theory and Issues for Practice. 1st Edn., Palgrave Macmillan, Basingstoke, ISBN-10: 0333964101, pp: 288.

Scharf, M., S. Shulman and L. Avigad-Spitz, 2005. Sibling relationships in emerging adulthood and in adolescence. J. Adolescent Res., 20: 64-90. DOI: $10.1177 / 0743558404271133$

Shortt, J.W., D.M. Capaldi, T.J. Dishion, L. Bank and L.D. Owen, 2003. The role of adolescent friends, romantic partners and siblings in the emergence of the adult antisocial lifestyle. J. Family Psychol., 17: 521-533. DOI: 10.1037/0893-3200.17.4.521

Slomkowski, C., R. Rende, K.J. Conger, R.L. Simons and R.D. Conger, 2001. Sisters, brothers and delinquency: Evaluating social influence during early and middle adolescence. Child Dev., 72: 271-283. DOI: $10.1111 / 1467-8624.00278$

Slomkowski, C., R. Rende, S. Novak, E. LloydRichardson and R. Niaura, 2005. Sibling effects on smoking in adolescence: Evidence for social influence from a genetically informative design. Addiction, 100: 430-438. DOI: $10.1111 / \mathrm{j} .1360-0443.2004 .00965 . \mathrm{x}$

Snyder, J., L. Bank, B. Burraston, A. Kazak and L. Kramer, 2005. The consequences of antisocial behavior in older male siblings for younger brothers and sisters. J. Family Psychol., 19: 643-653.

DOI: $10.1037 / 0893-3200.19 .4 .643$
Solmeyer, A.R., S.M. McHale and A.C. Crouter, 2014. Longitudinal associations between sibling relationship qualities and risky behavior across adolescence. Dev. Psychol., 50: 600-610. DOI: 10.1037/a0033207

Tucker, C.T., S.M. McHale and A.C. Crouter, 2001. Conditions of sibling support in adolescence. J. Family Psychol., 15: 254-271.

DOI: $10.1037 / 0893-3200.15 .2 .254$

Watt, B., K. Howells and P. Delfabbro, 2004. Juvenile recidivism: Criminal propensity, social control and social learning theories. Psychiatry Psychol. Law, 11: 141-153. DOI: 10.1375/pplt.2004.11.1.141

Whiteman, S., D. Jensen and A. Maggs, 2014. Similarities and differences in adolescent siblings' alcohol-related attitudes, use and delinquency: Evidence for convergent and divergent influence processes. J. Youth Adolescence, 43: 687-697. DOI: 10.1007/s10964-013-9971-z

Willetts, M.C., S. Sprecher and F.D. Beck, 2004. Overview of sexual practices and Attitudes within Relational Contexts. In: The Handbook of Sexuality in Close Relationships, Harvey, J.H., A. Wenzel and S. Sprecher (Eds.), pp: 57-86. 